\title{
Aromatic Amines Exert Contrasting Effects on the Anticoagulant Effect of Acetaldehyde upon APTT
}

\author{
La'Teese Hall, Sarah J. Murrey, and Arthur S. Brecher \\ Department of Chemistry, Bowling Green State University, Bowling Green, OH 43403, USA \\ Correspondence should be addressed to Arthur S. Brecher; artbrec@bgsu.edu
}

Received 12 June 2014; Revised 29 September 2014; Accepted 30 September 2014; Published 8 December 2014

Academic Editor: Bashir A. Lwaleed

Copyright (C) 2014 La'Teese Hall et al. This is an open access article distributed under the Creative Commons Attribution License, which permits unrestricted use, distribution, and reproduction in any medium, provided the original work is properly cited.

\begin{abstract}
The pharmacological effects of amphetamine, procaine, procainamide, DOPA, isoproterenol, and atenolol upon activated partial thromboplastin time in the absence and presence of acetaldehyde have been investigated. In the absence of acetaldehyde, amphetamine and isoproterenol exhibit a procoagulant effect upon activated partial thromboplastin time, whereas atenolol and procaine display anticoagulant effects upon activated partial thromboplastin time. DOPA and procainamide do not alter activated partial thromboplastin time. Premixtures of procaine with acetaldehyde produce an additive anticoagulant effect on activated partial thromboplastin time, suggesting independent action of these compounds upon clotting factors. Premixtures of amphetamine with acetaldehyde, as well as atenolol with acetaldehyde, generate a detoxication of the anticoagulant effect of acetaldehyde upon activated partial thromboplastin time. A similar statistically significant decrease in activated partial thromboplastin time is seen when procainamide is premixed with acetaldehyde for 20 minutes at room temperature. Premixtures of DOPA and isoproterenol with acetaldehyde do not affect an alteration in activated partial thromboplastin time relative to acetaldehyde alone. Hence, a selective interaction of atenolol, procaine, and amphetamine with acetaldehyde to produce detoxication of the acetaldehyde is suggested, undoubtedly due to the presence of amino, hydroxyl, or amide groups in these drugs.
\end{abstract}

\section{Introduction}

The physiological and pharmacological effects of alcohol upon brain and CNS function have been the subject of many studies. Ethanol is readily metabolized in the body to $\mathrm{CO}_{2}$ and $\mathrm{H}_{2} \mathrm{O}$ by well-established enzymatic pathways (reviewed in [1]). Acetaldehyde (AcH), the primary metabolite in ethanol metabolism, is a highly reactive molecule which reacts readily with nucleophiles [2-4]. Among these compounds are amines, amides, imidazoles, thiols, and hydroxyls which are found in proteins, nucleic acids, select carbohydrates, and lipids. In an earlier communication, it was reported that highly reactive biogenic amine hormones, such as dopamine, epinephrine, serotonin, norepinephrine, and histamine, each of which contain primary or secondary amines, or hydroxyl groups, appear to readily react with $\mathrm{AcH}$ at room temperature (RT) and to "detoxify" the $\mathrm{AcH}$, as evidenced by their capacity to reduce the anticoagulant effect of $\mathrm{AcH}$ on activated partial thromboplastin time (APTT) upon preincubation of the amines with $\mathrm{AcH}$ at room temperature (RT) [5]. It was further suggested that covalent interaction of the $\mathrm{AcH}$ with the biogenic amines would also "neutralize" their hormonal influences. As a consequence of these earlier investigations a new study of the effect of drugs with neurological impacts upon $\mathrm{AcH}$, as followed by APTT, was initiated. In the study presented herein, the effects of amphetamine, procaine, procainamide, atenolol, and isoproterenol upon $\mathrm{AcH}$ are explored and compared with that of DOPA, the biological precursor to catecholamines and melanin. The ability of AcH-exposed drugs to prolong coagulation times, as a measure of pharmacological function, was investigated.

\section{Materials and Methods}

Procainamide, lot \#54F-0048, procaine-HCl, lot \#125K0697, isoproterenol, D-amphetamine, L-DOPA, lot \#077K1844, and 5-atenolol, lot $\# 044 \mathrm{~K} 3485$, were purchased from Sigma-Aldrich Corporation, St. Louis, MD. APTT reagent, 
lot \#2006-02-02/527313A, $0.025 \underline{\underline{\mathrm{M}}} \mathrm{CaCl}_{2}$, lot \#05-172004/5006872, Ci-Trol coagulation control, Level I, lots \#2009-02-05/508114, 2006-01-19/538162/245, and 2010-0607/548137/255, were obtained from Dade Behring, Marburg. Assess TM Level I plasma lot \#N1106614 was obtained from Instrumentation Laboratory Company, Lexington, MA. Brockman I aluminum oxide, lot \#0791DY, was purchased from Aldrich Chemical Company, Milwaukee, WI. Acetaldehyde (AcH), 99\%, batch \#00339MB, was secured from Sigma-Aldrich and passed through short columns of aluminum oxide in order to remove oxidation products. It was subsequently stored under $\mathrm{N}_{2}$ at $-20^{\circ} \mathrm{C}$ until further use.

APTT assays were carried out as originally described elsewhere [6]. A fibrosystem fibrometer precision coagulation timer, model 5, Becton, Dickinson and Company, Cockeysville, MD, was employed to assay the APTTs.

\section{Methods}

3.1. Effect of Amphetamine Concentration on APTT. To $90 \mu \mathrm{L}$ of reconstituted plasma was added $10 \mu \mathrm{L}$ of ISB or $10 \mu \mathrm{L}$ of $10^{-1}, 10^{-2}$, or $10^{-3} \mathrm{M}$ amphetamine. The solutions were mixed in fibrometer cups and stored for $20 \mathrm{~min}$ at RT. Subsequently, $100 \mu \mathrm{L}$ of APTT reagent at $37^{\circ} \mathrm{C}$ was added thereto and the mixtures were incubated at $37^{\circ} \mathrm{C}$ for an additional five min, after which time $100 \mu \mathrm{L}$ of $0.025 \mathrm{M} \mathrm{CaCl}$ at $37^{\circ} \mathrm{C}$ was delivered in order to initiate the clotting reaction.

3.2. Effect of Amphetamine and AcH upon APTT. To $90 \mu \mathrm{L}$ of reconstituted plasma was added $20 \mu \mathrm{L}$ of ISB to serve as a control. To a second $90 \mu \mathrm{L}$ aliquot of plasma were added $10 \mu \mathrm{L}$ of ISB and $10 \mu \mathrm{L}$ of $0.1 \underline{\mathrm{M}}$ amphetamine to give a final concentration of $4.5 \times 10^{-2} \underline{\overline{\mathrm{M}}}$ amphetamine in plasma. To a third aliquot of plasma were added $10 \mu \mathrm{L}$ of $447 \mathrm{mM} \mathrm{AcH}$ and $10 \mu \mathrm{L}$ ISB, to give an $\mathrm{AcH}$ concentration of $20.3 \overline{\mathrm{mM}}$ in plasma. Lastly, to a fourth aliquot of $90 \mu \mathrm{L}$ of plasma was added $20 \mu \mathrm{L}$ of a mixture of equal volumes of amphetamine and $447 \mathrm{mM}$ AcH (which was stored for five min at RT). Each sample was mixed and stored for $20 \mathrm{~min}$ at RT, after which time $100 \mu \mathrm{L}$ of APTT reagent at $37^{\circ} \mathrm{C}$ was added thereto. The mixture was subsequently stored at $37^{\circ} \mathrm{C}$ for five min prior to initiation of clotting upon addition of $100 \mu \mathrm{L}$ of $0.025 \mathrm{mM}$ $\mathrm{CaCl}_{2}$ at $37^{\circ} \mathrm{C}$.

3.3. Effect of Isoproterenol Concentration on APTT. To fibrometer cups containing $90 \mu \mathrm{L}$ of reconstituted Level I human plasma were added $10 \mu \mathrm{L}$ of ISB and $10 \mu \mathrm{L}$ of $10^{-1} \underline{\mathrm{M}}, 10^{-2} \underline{\mathrm{M}}$, or $10^{-3} \mathrm{M}$ isoproterenol in ISB. The solutions were mixed, stoppered, and stored for $20 \mathrm{~min}$ at RT. Subsequently, $100 \mu \mathrm{L}$ APTT reagent was added thereto at $37^{\circ} \mathrm{C}$ and the mixture was further stored at $37^{\circ} \mathrm{C}$ for five min. Lastly, $0.025 \underline{\underline{M ~ C a C l}}$ $(100 \mu \mathrm{L})$ at $37^{\circ} \mathrm{C}$ was added to initiate clotting.

3.4. Effect of Isoproterenol and AcH upon APTT. To $90 \mu \mathrm{L}$ aliquots of plasma in fibrometer cups was added $20 \mu \mathrm{L}$ ISB or three alternative mixtures: (1) $10 \mu \mathrm{L}$ ISB $+10 \mu \mathrm{L} 10^{-1} \underline{\underline{\mathrm{M}}}$ isoproterenol; (2) $10 \mu \mathrm{L} \mathrm{ISB}+10 \mu \mathrm{L} 223.5 \mathrm{mM}$ AcH; and $\overline{(3)}$ $20 \mu \mathrm{L}$ of a $1: 1$ mixture of $10^{-1} \underline{\mathrm{M}}$ isoproterenol and $223.5 \mathrm{mM}$ AcH. The solutions were mixed, stoppered, and stored at $\overline{\overline{\mathrm{RT}}}$ for $20 \mathrm{~min}$, after which time $100 \mu \mathrm{L}$ of APTT reagent at $37^{\circ} \mathrm{C}$ was added thereto. After further storage at $37^{\circ} \mathrm{C}$ for five min,

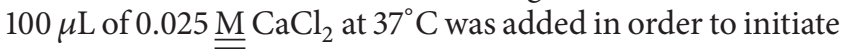
clotting.

3.5. Effect of Atenolol and AcH upon APTT. To six $90 \mu \mathrm{L}$ aliquots of Level I plasma in fibrometer cups was added either $20 \mu \mathrm{L}$ ISB ( $1^{\circ}$ control); $10 \mu \mathrm{L}$ ISB and $10 \mu \mathrm{L}$ of $0.075 \underline{\underline{\mathrm{M}}}$ atenolol (in $30 \%$ ethanol); $10 \mu \mathrm{L}$ ISB and $10 \mu \mathrm{L}$ of $223 \mathrm{~m} \overline{\underline{M}}$ $\mathrm{AcH} ; 10 \mu \mathrm{L}$ of $0.075 \underline{\mathrm{M}}$ atenolol, followed five minutes later by $10 \mu \mathrm{L}$ of $223 \mathrm{mM} \overline{\mathrm{A}} c \mathrm{H} ; 10 \mu \mathrm{L}$ of $223 \mathrm{mM} \mathrm{AcH}$, followed five minutes later by $10 \mu \mathrm{L}$ of $0.075 \underline{\mathrm{M}}$ atenolol; or $20 \mu \mathrm{L}$ of a 1:1 mixture of atenolol: AcH which had been stored at RT for five min. Upon standing at RT for five min, $100 \mu \mathrm{L}$ of APTT reagent was added thereto and the mixture was incubated at $37^{\circ} \mathrm{C}$ for an additional five min. Subsequently, clotting was initiated by addition of $100 \mu \mathrm{L}$ of $0.025 \underline{\mathrm{M} \mathrm{CaCl}} 2$ at $37^{\circ} \mathrm{C}$. In separate experiments, the effect of atenolol-treated plasma was compared to control plasma containing approximately $1 \%$ ethanol.

3.6. Effect of Procainamide, Procaine, DOPA, and AcH upon APTT. To six fibrometer cups were added $90 \mu \mathrm{L}$ of plasma and each of the following: (1) $20 \mu \mathrm{L}$ ISB; (2) $10 \mu \mathrm{L}$ ISB and $10 \mu \mathrm{L}$ of $0.05 \mathrm{M}$ procainamide (to a final concentration of $4.5 \mathrm{mM}$ in plasma); (3) $10 \mu \mathrm{L}$ ISB and $10 \mu \mathrm{L}$ of $223.5 \underline{\mathrm{M} \mathrm{AcH}}$ (to a final concentration of $20.3 \mathrm{mM}$ in plasma); (4) $\overline{\overline{\text { ten }}} \mu \mathrm{L}$ of procainamide, followed ten minutes later by $10 \mu \mathrm{L}$ of $\mathrm{AcH}$; (5) ten $\mu \mathrm{L}$ of $\mathrm{AcH}$, followed ten minutes later by $10 \mu \mathrm{L}$ of procainamide; (6) $20 \mu \mathrm{L}$ aliquot of a 1:1 mixture of procainamide and $\mathrm{AcH}$ which had been previously stored and stoppered at RT for ten min. After standing at RT for ten $\min , 100 \mu \mathrm{L}$ of APTT reagent at $37^{\circ} \mathrm{C}$ was added thereto, and the cups were incubated at $37^{\circ} \mathrm{C}$ for five min. Subsequently, clotting was initiated upon addition of $100 \mu \mathrm{L}$ of $0.025 \mathrm{M} \mathrm{CaCl}_{2}$. Four additional fibrometer cups contained a control stored at RT for $20 \mathrm{~min}$, as well as plasma-procainamide, plasma-AcH, and plasma/procainamide-AcH premixtures stored for $20 \mathrm{~min}$ at RT. In an analogous manner, the effects of procaine and DOPA upon $\mathrm{AcH}$ were studied utilizing $9.1 \mathrm{mM}$ procaine in plasma and $0.9 \mathrm{mM}$ DOPA in plasma (due to solubility limitations).

3.7. Statistical Analyses. The data were analyzed by application of student's $t$-test. $P$ values $\leq 0.05$ were assumed to be statistically significant. In all groups of experiments, $n=$ $4,5,6,7$, or 10 , as indicated above in Methods section. 


\section{Results}

The neurohormone, DOPA, and the neurotropic drugs, isoproterenol, atenolol, amphetamine, procaine, and procainamide each contain the benzene ring and various structural modifications. Each one presents a diverse picture relating to its effect upon APTT and its influence on the anticoagulant effect of $\mathrm{AcH}$ as a consequence of the presence/absence of functional groups which may interact with $\mathrm{AcH}$. In essence, it was observed that amphetamine and isoproterenol exhibit a procoagulant effect upon APTT whereas atenolol and procaine display an anticoagulant effect upon APTT. Procainamide and DOPA have no statistical effect upon APTT under the conditions employed. AcH prolongs the APTT. Premixtures of amphetamine, atenolol, procaine, and procainamide with $\mathrm{AcH}$ exhibit a "detoxication" of the anticoagulant effect of $\mathrm{AcH}$, that is, reduction in the anticoagulant activity of AcH. Successive additions of atenolol and $\mathrm{AcH}$ to plasma produce an additive anticoagulant effect, as does procaine. Successive additions of procainamide and AcH to plasma do not exhibit an additive anticoagulant effect with a 10-min exposure to plasma.

4.1. Effect of Atenolol and Acetaldehyde upon APTT. Atenolol additions to plasma to concentrations of $10^{-2} \underline{\underline{M}}$ and $5 \times$ $10^{-3} \mathrm{M}$ produced APTTs of $53.6 \pm 0.8 \mathrm{sec}(n=4 ; P=0)$

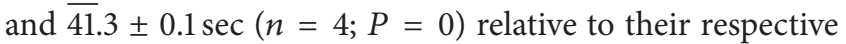
controls of $39.7 \pm 0.6$ and $37.8 \pm 0.3 \mathrm{sec}(n=4)$ (Figure 1). At concentrations of $1 \times 10^{-3} \underline{\underline{M}}$ and $1 \times 10^{-4} \underline{\underline{M}}$, a slight procoagulant effect was observed with $P=0.07$, approaching significance for the former concentration and a statistically significant $P=0.01$ for the latter concentration. In studies involving both atenolol and acetaldehyde, it was noted that $7.5 \times 10^{-3} \underline{\underline{M}}$ atenolol in plasma and $20.3 \mathrm{~m} \underline{\underline{M}}$ acetaldehyde in plasma each prolonged APTT, with values of $42.6 \pm 0.7(P=$ $0.002)$ and $42.8 \pm 0.9 \sec (P=0.002)$, respectively, relative to a control of $34.0 \pm 0.4 \mathrm{sec}(n=4)$ (Figure 2). Preincubation time of plasma with the drug was $5 \mathrm{~min}$ at RT. Hence, atenolol and acetaldehyde each exhibited anticoagulant effects. When atenolol was added initially to plasma for five min at RT and acetaldehyde was subsequently added for an additional five min prior to concluding the APTT, a value of $54.5 \pm$ $0.8 \mathrm{sec}(P=0)$ was obtained. The atenolol and AcH effects on plasma were additive. When the order of addition of the reagents to plasma was reversed, an APTT of $59.0 \pm 1.8 \mathrm{sec}$ $(P=0)$ was noted. However, when atenolol and acetaldehyde were mixed and preincubated at RT for five min prior to addition to plasma for an additional five min at RT before concluding the APTT, an APTT of $45.9 \pm 2.4 \mathrm{sec}(P=0)$ was observed. The drop in APTT from 54.5 ${ }^{\prime \prime}$ to $45.9^{\prime \prime}$ suggested that atenolol partially inactivated the effect of acetaldehyde by exerting a detoxifying effect. The increase in APTT by the addition of acetaldehyde to plasma prior to addition of atenolol reflected the effect of increased exposure time of plasma to acetaldehyde.

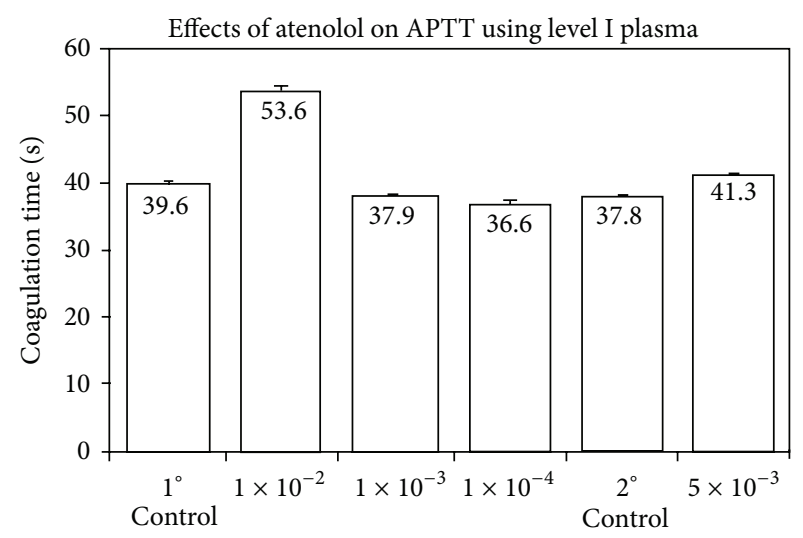

FIGURE 1: Effects of atenolol upon APTT using Level I plasma $(n=4$; $P=0$ for $1 \times 10^{-2} \underline{\underline{M}}$ and $5 \times 10^{-3} \underline{\underline{M}}$ atenolol $)(n=4 ; P=0.07$ for 1 $\times 10^{-3} \underline{\underline{M}}$ atenolol and $P=0.01$ for $1 \times 10^{-4} \underline{\underline{M}}$ atenolol).

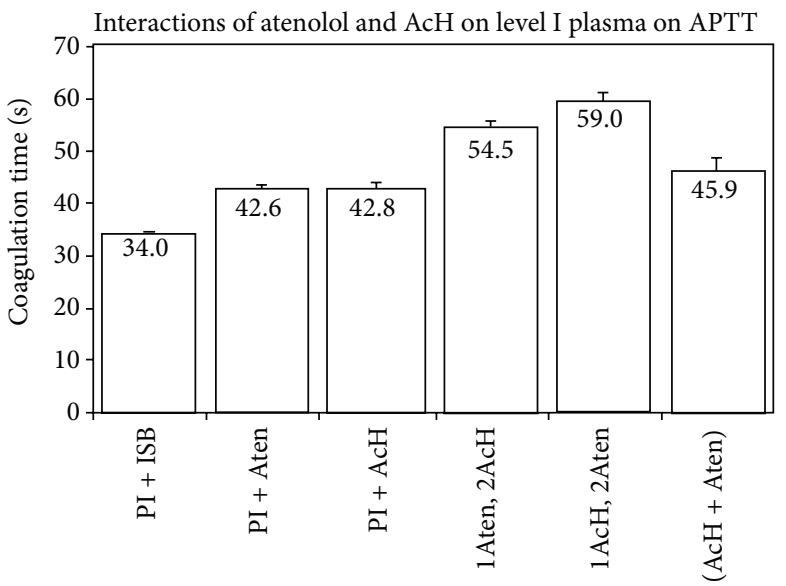

FIgURE 2: Interactions of atenolol and $\mathrm{AcH}$ on Level I plasma on APTT $(n=4 ; P=0.002$ for atenolol and for AcH; $P=0$ for 1 Aten $/ 2 \mathrm{AcH}$ and for $1 \mathrm{AcH} / 2$ Aten; $P=0.02$ for the $\mathrm{AcH}$ and Aten premixture).

4.2. Effect of Amphetamine and Acetaldehyde. Figure 3 indicates that $0.01 \mathrm{M} \mathrm{D}$-amphetamine exerted a statistically significant procoagulant effect upon APTT upon preincubation with plasma for $20 \mathrm{~min}$ at RT, with an APTT of $24.3 \pm 0.8 \mathrm{sec}$ $(P \leq 0.02)$ relative to a control of $28.4 \pm 1.1 \mathrm{sec}(n=5)$. At $10^{-3}$ and $10^{-4} \underline{\underline{M}}$ levels of amphetamine, there was no significant difference between control and experimental values. In an examination of the interactive effect of amphetamine and acetaldehyde upon the APTT reaction, it was observed that $0.01 \mathrm{M}$ amphetamine, upon exposure to plasma for $20 \mathrm{~min}$ at RT, exhibited an APTT of $26.4 \pm 0.8 \mathrm{sec}$ relative to a control plasma of $29.5 \pm 0.9 \mathrm{sec}$, whereas $40.6 \mathrm{mM}$ acetaldehyde under the same conditions affected an APTT of $48.5 \pm 2.2 \mathrm{sec}$ (Figure 4). A premixture of acetaldehyde and amphetamine, standing at RT for $20 \mathrm{~min}$ prior to incubation with plasma for $20 \mathrm{~min}$, resulted in an APTT of $35.4 \pm 1.6 \mathrm{sec}(n=10$, $P \leq 0.01)$ corresponding to a decrease of $13.1 \mathrm{sec}$ in clotting time and a detoxication of the acetaldehyde by amphetamine. 


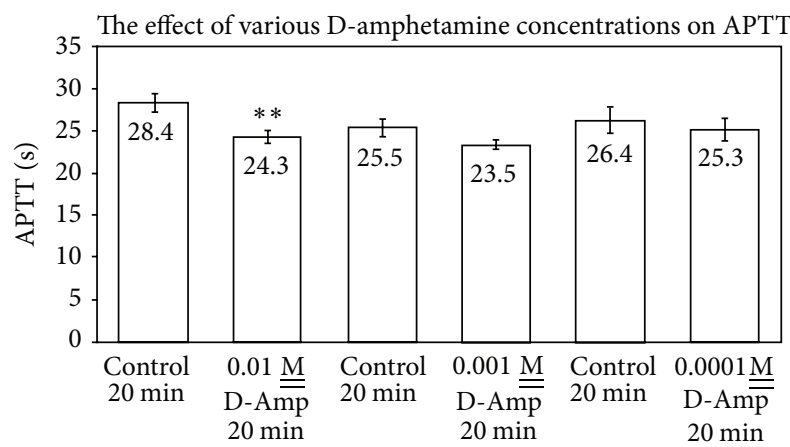

FIGURE 3: Effect of various D-amphetamine concentrations on APTT $(n=5 ; P \leq 0.02$ for $0.01 \underline{\mathrm{M}} \mathrm{D}$-Amp) $(n=10 ; P \leq 0.01$ for the $20 \mathrm{~min}$ D-Amp-AcH mixture). $* *$ indicate that $P \leq 0.05$ relative to the control APTTs.

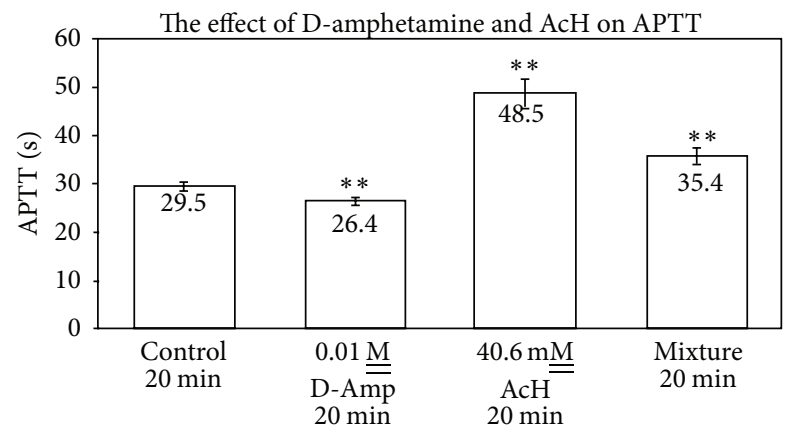

Figure 4: The effect of D-amphetamine and AcH on APTT ( $n=10$; $P \leq 0.01$ for the D-Amp-AcH mixture).

4.3. Effect of Isoproterenol and Acetaldehyde upon APTT. As indicated in Figure 5, $1 \times 10^{-2} \underline{\underline{M}}$ isoproterenol exerts a small but statistically significant procoagulant effect upon APTT since its clotting time is $28.0 \pm 0.6 \mathrm{sec}$ relative to the control of $31.9 \pm 1.3 \mathrm{sec}(n=4, P=0.03)$. At concentrations of isoproterenol at $10^{-3}$ and $10^{-4} \underline{\mathrm{M}}$, no statistical difference is seen as compared to controls. The data in Figure 6 show that a premixture of isoproterenol and acetaldehyde exhibits essentially identical APTTs as acetaldehyde alone, with values of $38.7 \pm 1.1 \mathrm{sec}$ and $38.4 \pm 1.8 \mathrm{sec}$, relative to the control of $31.9 \pm 1.1 \mathrm{sec}$. In this series $(n=6, P=0.01)$, the isoproterenol exhibited a procoagulant effect of $27.3 \pm$ $1.1 \mathrm{sec}$. Hence, isoproterenol did not apparently react with acetaldehyde or affect its toxicity on APTT.

4.4. Effect of Procaine and Acetaldehyde upon APTT. Figure 7 shows that $0.01 \mathrm{M}$ procaine and $20.3 \mathrm{mM}$ acetaldehyde each prolong APTT, relative to control APTT of $29.6 \pm 0.8 \mathrm{sec}$, with APTTs of $34.9 \pm 0.9$ and $34.8 \pm 0.5 \mathrm{sec}$, respectively ( $P=0.001$, resp.), when preincubation times of procaine or acetaldehyde are for $10 \mathrm{~min}$ at RT, indicating anticoagulant effects $(n=6)$. When procaine and acetaldehyde at the same concentrations are preincubated with plasma for $20 \mathrm{~min}$ at $\mathrm{RT}$, the respective APTTs are $34.5 \pm 0.6 \mathrm{sec}$ and $36.6 \pm 0.3 \mathrm{sec}$, relative to a control of $28.8 \pm 0.5 \mathrm{sec}(P=0.0001$, resp. $)$.

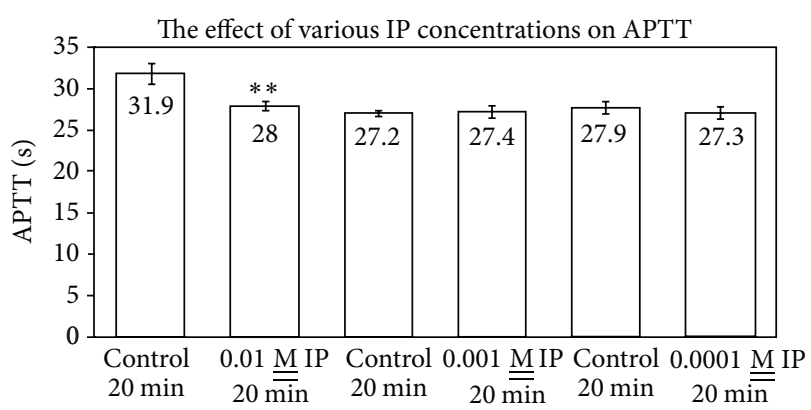

FIGURE 5: Effect of various isoproterenol concentrations upon APTT $(n=4 ; P=0.03$ for $0.01 \underline{\underline{M}} \mathrm{IP})$.

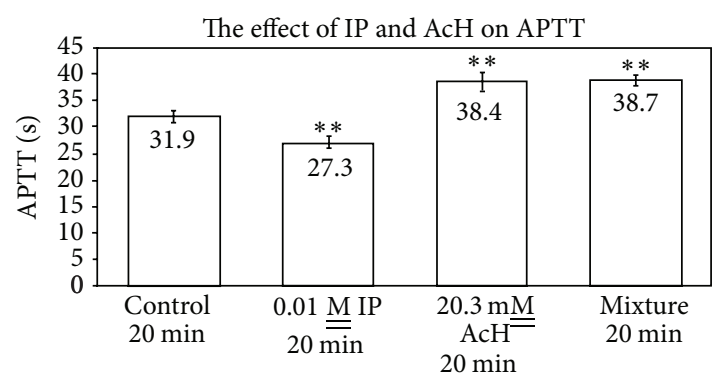

FIGURE 6: Effect of isoproterenol and acetaldehyde on APTT ( $n=6$; $P=0.01)$.

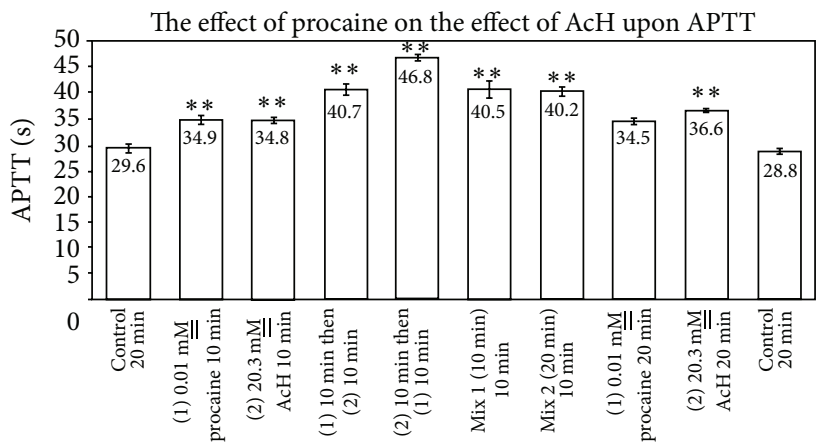

FIGURE 7: Effect of procaine and acetaldehyde upon APTT $(n=6$; $P=0.001)$.

The increase in the anticoagulant effect of acetaldehyde with longer preincubation times with plasma has been previously reported [6]. Premixtures of procaine with acetaldehyde, upon storage for 10 or $20 \mathrm{~min}$ at RT before addition to plasma for an additional $10 \mathrm{~min}$ at RT before assay for APTT, resulted in APTTs of $40.5 \pm 1.6 \mathrm{sec}$ and $40.2 \pm 0.9 \mathrm{sec}$, respectively $(P=0.0001$, resp. $)$. These essentially reflect an additive effect of each drug upon the components of the coagulation cascade. When procaine is added to plasma first for a tenminute preincubation, followed by acetaldehyde second for an additional ten minutes, an APTT of $40.7 \pm 1.0 \mathrm{sec}$ is noted. When the order of addition to plasma is reversed, an APTT of $46.8 \pm 0.6 \mathrm{sec}$ is obtained, reflecting an increase in clotting 


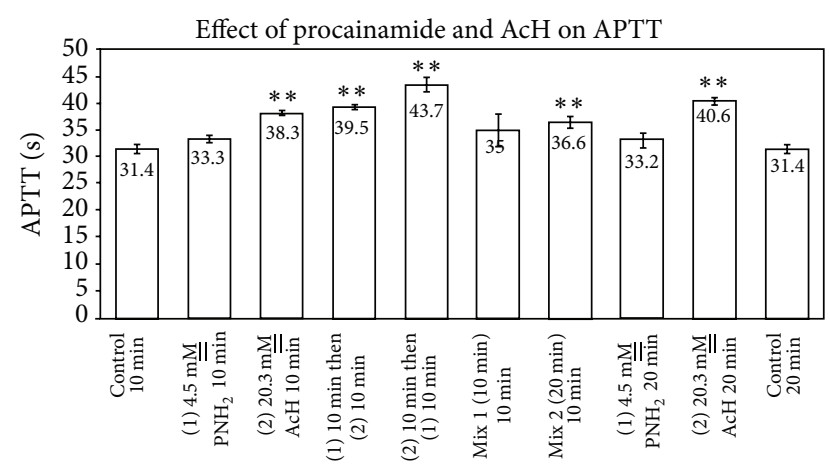

FIGURE 8: Effect of procainamide and acetaldehyde upon APTT $(n=$ 6; $P=0.0001$ for $\mathrm{AcH}$; for 1 procainamide, $2 \mathrm{AcH}$; and for $1 \mathrm{AcH}$, 2 procainamide; $P=0.0035$ for the 20 min premix of procainamide with $\mathrm{AcH}$ and is n.s. (0.3) for the 10 min premix).

time as a consequence of prolonged exposure of plasma to acetaldehyde.

4.5. Effect of Procainamide and Acetaldehyde upon APTT. Procainamide, $4.5 \mathrm{mM}$, and acetaldehyde, $20.3 \mathrm{mM}$, each prolonged APTT, relative to the control of $31.4 \pm 0.9 \mathrm{sec}$, with APTTs of $33.3 \pm 0.6 \mathrm{sec}$ and $38.3 \pm 0.4 \mathrm{sec}$, respectively, when preincubated with plasma at RT for ten min ( $n=6, P=0.0001$ for acetaldehyde). Whereas the acetaldehyde-containing plasma gave a statistically significant difference from the control, the procainamide value was not statistically different $(P=0.1)$ (Figure 8$)$. When incubations of procainamide and acetaldehyde with plasma were extended to $20 \mathrm{~min}$ at RT, APTTs of $33.2 \pm 1.4 \mathrm{sec}$ and $40.6 \pm 0.7 \mathrm{sec}$, respectively, relative to a control of $31.4 \pm 0.8 \mathrm{sec}$ were obtained. Acetaldehyde, again, affected a greater prolongation of clotting time in $20 \mathrm{~min}$ as compared to $10 \mathrm{~min}$. The procainamide-containing plasma did not statistically significantly alter APTT in 20 min as compared to its control plasma. Whereas $20.5 \mathrm{mM}$ acetaldehyde added to plasma produced APTTs of $38 . \overline{\overline{3}} \pm 0.4$ and $40.6 \pm$ $0.7 \mathrm{sec}(P=0.0001$ in both cases $)$ in 10 and $20 \mathrm{~min}$, respectively, 10 - and 20-min premixtures of procainamide with acetaldehyde generated APTTs of $35 \pm 3.2$ and 36.6 $\pm 1.1 \mathrm{sec}$, respectively. The latter $(20 \mathrm{~min})$ values exhibited statistical differences between acetaldehyde alone and the acetaldehyde-procainamide premixture suggesting a detoxication of acetaldehyde by procainamide as a consequence of interaction. When procainamide was preincubated with plasma for ten min at RT after which acetaldehyde was subsequently added thereto, an APTT of $39.5 \pm 0.4 \mathrm{sec}$ was seen. When the order of addition of the compounds was reversed, an APTT of $43.7 \pm 1.4 \mathrm{sec}$ was noted. The increase in APTT was a reflection of the increased time of exposure of plasma to acetaldehyde.

4.6. Effect of DOPA and Acetaldehyde on APTT. Figure 9 shows that $0.01 \mathrm{M}$ DOPA does not significantly affect APTT after preincubation for 10 or $20 \mathrm{~min}(n=7)(P=0.92$, n.s.). Whereas $20.3 \mathrm{mM}$ acetaldehyde significantly prolongs

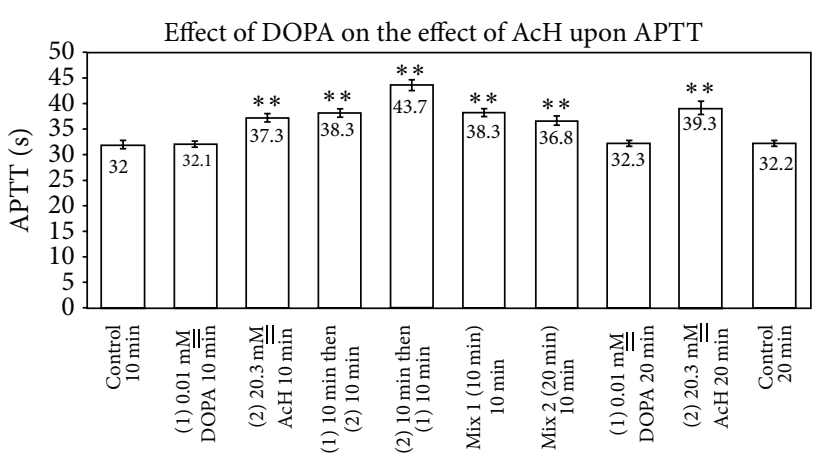

Figure 9: Effect of DOPA and acetaldehyde upon APTT ( $n=7$; $P \leq 0.05$ relative to the controls).

APTT upon preincubation with plasma for $10 \mathrm{~min}(P=$ $0.0001)$ as well as $20 \mathrm{~min}(P=0.0002)$, premixtures of acetaldehyde with DOPA for $10 \mathrm{~min}$ or $20 \mathrm{~min}$ do not differ statistically from acetaldehyde alone in their APTT values. Preincubation of acetaldehyde alone with plasma gives a higher APTT after $20 \mathrm{~min}$ contact as compared to $10 \mathrm{~min}$ contact ( $39.3 \mathrm{sec}$ relative to $37.3 \mathrm{sec}$ ), confirming all previous time course studies. Similarly, order of addition of reagents affected APTT since addition, first, of acetaldehyde to plasma with a 10 -min contact time, followed by addition of DOPA thereto, gave an elevated APTT relative to the reverse order of addition ( $43.7 \mathrm{sec}$. relative to $37.3 \mathrm{sec}$ ), once again suggesting that longer contact times for interaction of acetaldehyde with plasma give greater prolongation of clotting times. Interestingly, however, it was observed that a 20 -min premixture presented an APTT of $36.8 \pm 1.0 \mathrm{sec}$ whereas the APTT obtained when acetaldehyde was preincubated with plasma for $10 \mathrm{~min}$ prior to a second $10 \mathrm{~min}$ preincubation with added DOPA was $43.7 \pm 1.0 \mathrm{sec}$, inferring that an interaction between acetaldehyde and DOPA has occurred in the 20-min preincubation time.

\section{Discussion}

The comparisons and contrasts between the structures as well as physiological and pharmacological effects of aromatic drugs such as amphetamine, isoproterenol, atenolol, procaine, and procainamide relative to the naturally occurring DOPA are marked. Furthermore, their response to interaction with $\mathrm{AcH}$, the primary metabolite in alcohol metabolism, adds to the fascinating diversity in physiological and pharmacological responses. The comparison of these compounds with results obtained in earlier studies on such biogenic amine hormones as dopamine, epinephrine, norepinephrine, serotonin, and histamine also bears notice [5].

In contrast to the biogenic amines listed above (DA, E, $\mathrm{NE}, 5-\mathrm{HT}$, and $\mathrm{H}$ ), all of the compounds in the current study, with the exception of the naturally occurring DOPA, namely, amphetamine, isoproterenol, atenolol, procaine, and procainamide, are drugs. Each is aromatic and each bears a broad resemblance to $\mathrm{E}, \mathrm{NE}$, and DA in that they contain the benzene ring. DOPA, procainamide, procaine, and amphetamine contain the primary amine group. Procaine, 
procainamide, and isoproterenol contain $2^{\circ} \mathrm{N}$ 's, whereas atenolol, isoproterenol, and DOPA also contain hydroxyl groups (which should be capable of reacting with aldehydic functional groups). Procainamide, lastly, also contains a $1^{\circ}$ amide group. Hence, many groups are susceptible to reactivity with $\mathrm{AcH}$. Whereas each drug contains nucleophiles and rings, they differ amongst themselves in their ability to affect the APTT reaction. Accordingly, amphetamine and isoproterenol exhibit a procoagulant effect upon addition to plasma, whereas atenolol and procaine have an anticoagulant effect upon APTT. Procainamide and naturally occurring DOPA do not affect the APTT under the conditions employed. It should be noted that DA, the metabolic product of DOPA by decarboxylation, has a modest procoagulant effect upon APTT, as do EP and 5-H [5]. NE and histamine, however, do not statistically affect APTT [5].

Notwithstanding the similarities and diversities of the drugs studied herein with regard to nucleophilic properties and aromaticity, the difference in pharmacological effect upon APTT, relative to interactions of the drugs with $\mathrm{AcH}$, is striking. Amphetamine, which exhibited a small, but statistically significant, procoagulant effect upon APTT, had a profound "detoxifying" effect upon APTT as a consequence of premixing the drug for $20 \mathrm{~min}$ at $\mathrm{RT}$ with $\mathrm{AcH}$ prior to addition to plasma (Figures 3 and 4). Essentially, the major anticoagulant effect of AcH upon APTT was markedly reduced by premixing with amphetamine. Atenolol, which exhibits an anticoagulant effect upon APTT, similarly statistically reduces the anticipated APTT when premixtures thereof with $\mathrm{AcH}$ are added to plasma. Individually, Aten and $\mathrm{AcH}$ each prolong APTT (Figure 2). Premixtures thereof are far less than additive in their APTT effect suggesting an interaction of the two, leading to a partial detoxication. When Aten is added to plasma prior to $\mathrm{AcH}$, an APTT is recorded which is less than that when $\mathrm{AcH}$ is added first and Aten second. This is in agreement with earlier published results from this laboratory signifying that $\mathrm{AcH}$ affects a time-dependent increasing anticoagulant effect upon clotting time (PT). Although $\mathrm{AcH}$ reacts instantaneously with nucleophiles $[2,3]$, some reactions are reversible while others are irreversible $[7,8]$. Presumably, this would explain increases and some slight ultimate decreases in coagulation times over extended periods of time, as tertiary structures of some proteins/enzymes are altered. Of further note is the fact that successive addition of Aten and $\mathrm{AcH}$ to plasma lends an additive effect upon APTT, suggesting that each of these components reacts at different sites on proteins, resulting in anticoagulant effects, when they do not react with one another. Whereas procainamide alone has no significant anticoagulant effect on APTT, successive additions of procainamide and $\mathrm{AcH}$ to plasma for $10 \mathrm{~min}$ at $\mathrm{RT}$ result in an anticoagulant effect corresponding to that of $\mathrm{AcH}$ alone and statistically significant (Figure 8). Upon premixing procainamide and $\mathrm{AcH}$ for $10 \mathrm{~min}$ prior to addition to plasma, there is no statistically significant reduction in the anticoagulant activity. However, when the premixture stands at RT for $20 \mathrm{~min}$, a statistical drop in anticoagulant activity is observed, that is, a partial detoxication of the anticoagulant activity. This suggests that a slow reaction between $\mathrm{AcH}$ and procainamide, perhaps of a reversible nature, may be occurring. Of course, a reversible dissociation of $\mathrm{AcH}$ from the protein, with time, may also be occurring.

Procaine differs from procainamide in that the former exhibits an anticoagulant effect upon APTT, while successive additions of procaine and $\mathrm{AcH}$ to plasma produce an additive effect upon APTT, reflecting independent action of each compound upon protein components of the coagulation scheme (Figure 7). Interestingly, premixtures of procaine and $\mathrm{AcH}$ for $10 \mathrm{~min}$, as well as $20 \mathrm{~min}$, are reflected by an additive effect upon the APTT. This may be a reflection of the difference in reactivity of procaine, with an ester link, and procainamide, with an amide $\left(2^{\circ}\right.$ amine) link.

Isoproterenol and DOPA, with their procoagulant and nonstatistical effects upon APTT, appear also to exert no statistical effect upon APTT when premixed with $\mathrm{AcH}$ (Figures 6 and 9). In the case of isoproterenol, $\mathrm{AcH}$ alone and AcH-IP mixtures show identical APTTs (Figure 6). In the DOPA experiments, successive additions behave as though DOPA was ineffective in influencing APTT in the presence of AcH. Similarly, 10-min and 20-min mixtures of AcH with DOPA behaved as if DOPA were absent (Figure 9). These data differ markedly from those with dopamine, which has a slight procoagulant effect and which decreases the anticoagulant effect of $\mathrm{AcH}$ when added successively to plasma as a premix with AcH [5]. The aromatic amines, epi, norepi, 5-HT, and histamine, each lower the anticoagulant effect of $\mathrm{AcH}$ upon plasma when preincubated with AcH at RT [5].

Clinically, the drugs exhibit powerful effects. Amphetamines, as well as methamphetamine (MDMA) and cocaine, are linked with increased blood pressure, cardiac arrhythmias, stroke, TIAs, infarctions, and hemorrhages $[9,10]$. Amphetamines promote neurotransmission by blocking presynaptic uptake of catecholamines, thereby elevating their presence at the synapses, with the consequential saturation of postsynaptic receptors [10]. MDMA inhibits mitochondrial ALDH2 and cytosolic ALDH1 [11]. Long term serotonergic neurotoxicity of MDMA in rats is extended by ethanol as a result of the increased presence of acetaldehyde which inhibits ALDH1 and ALDH2 [12].

Isoproterenol, which is a $\beta_{1}-\beta_{2}$ adrenergic agonist, causes cardiac hypertrophy and myocardial infarction in mice and rats [13-20]. Galindo et al. [13] observed the modification of 865 genes by isoproterenol. Notably, however, caffeic acid lowers the extent of membrane damage by isoproterenol in male albino Wistar rats. Sesamol, neferine, and vitamin A protect rodents from damages by isoproterenol. Rats on an ethanol diet exhibit higher survival rates as a consequence of isoproterenol-induced MI. The alcoholic rats exhibited higher levels of $\mathrm{ADH}$ and $\mathrm{ALDH}[20]$.

The $\beta$-adrenergic blocker, atenolol, has antihypertensive, antianginal, and antiarrhythmic properties [21-27]. The antiarrhythmic effect is seen on administration of atenolol to rats with epinephrine-induced arrhythmia [26]. The combined application of ethanol and atenolol generates a reduced arrhythmic response in comparison to individual administration. Atenolol has been applicable for the treatment of 
ethanol-withdrawal syndrome [28, 29]. It also lowers the rate of reinfarction after an initial MI [23] thereby lowering mortality rates.

DOPA and dopamine are integrally related since DOPA is a metabolic product of tyrosine and dopamine is a sequential metabolic product of DOPA. Both are catecholamines and are precursors to norepinephrine and epinephrine. Together with 5-HT, they comprise biogenic amine hormones which decrease the anticoagulant effect of AcH upon APTT [5]. The most likely scenario involved is the formation of Schiff bases as well as hemiacetals and acetals between the $\mathrm{AcH}$ and the amines and hydroxyl moieties of these hormones, thereby detoxifying the $\mathrm{AcH}$ [5]. Johnson [30] noted in animal studies that lower levels of 5-HT are seen with an increase in alcoholic drinking. This may be reflected in the interaction of $\mathrm{AcH}$ with 5-HT to form Schiff bases. Sato et al. [31] have reported that patients treated with antiparkinsonism drugs who were on DOPA and dopamine agonists had elevated PTs. Among the most interesting developments in recent years is the report by Sandler et al. that 1-methyl-6,7-dihydroxy-1,2,3,4tetrahydroisoquinoline, also known as salsolinol, was seen in the urine of parkinsonism patients under treatment with LDOPA [32]. Further studies with rats and humans have led to the observation of salsolinol in rat adrenals and in the urine of alcoholics [33]. Salsolinol was reported to be a condensation product of dopamine and $\mathrm{AcH}$ [34]. N-Methyl salsolinol, a metabolic product of salsolinol, induced apoptosis in neurons [35] as a neurotoxin [36]. Hence, DOPA and dopamine engage both Parkinson's disease and AcH, although DOPA is not an agent utilizable for alcoholism [37].

Unlike the afore discussed metabolites and drugs, procaine and procainamide have not been explored for their interactions with alcoholism or acetaldehyde to any major extent. However, some effects of paraldehyde have been briefly studied in earlier years [38-40]. Interactions of biogenic amine hormones with $\mathrm{AcH}$, as well as metabolic studies on their catabolic products, remain an ongoing field of interest.

\section{Conflict of Interests}

The authors declare that there is no conflict of interests regarding the publication of this paper.

\section{Acknowledgment}

The authors express their deep appreciation to Professor Robert Harr, Chairperson of the Medical Technology Program at BGSU, for his generous contribution of plasma and APTT reagents which were used during this investigation.

\section{References}

[1] A. S. Brecher, "The effect of acetaldehyde on plasma," in Comprehensive Handbook of Alcohol Related Pathology, V. R. Preedy and R. Watson, Eds., pp. 1223-1244, Academic Press, Elsevier Science, London, UK, 2005.

[2] H. Fraenkel-Conrat and H. S. Olcott, "Reaction of formaldehyde with proteins. VI. Crosslinking of amino groups with phenol, imidazole, or indole groups," The Journal of Biological Chemistry, vol. 174, pp. 827-843, 1948.

[3] H. Fraenkel-Conrat and H. S. Olcott, "The reaction of formaldehyde with proteins. V. Cross-linking between amino and primary amide or guanidyl groups," Journal of the American Chemical Society, vol. 70, no. 8, pp. 2673-2684, 1948.

[4] S. Ratner and H. T. Clarke, "The action of formaldehyde upon cysteine," Journal of the American Chemical Society, vol. 59, no. 1, pp. 200-206, 1937.

[5] S. J. Murrey and A. S. Brecher, "Interaction of biogenic amine hormones with acetaldehyde," Digestive Diseases and Sciences, vol. 55, no. 1, pp. 21-27, 2010.

[6] A. S. Brecher and M. T. Adamu, "Short- and long-term effects of acetaldehyde on plasma," Alcohol, vol. 26, no. 1, pp. 49-53, 2002.

[7] D. J. Tuma, T. Hoffman, and M. F. Sorrell, "The chemistry of acetaldehyde-protein adducts," Alcohol and Alcoholism, vol. 1, pp. 271-276, 1991.

[8] M. F. Sorrell, D. J. Tuma, and A. J. Barak, "Evidence that acetaldehyde irreversibly impairs glycoprotein metabolism in liver slices," Gastroenterology, vol. 73, no. 5, pp. 1138-1141, 1977.

[9] T. P. Enevoldson, "Recreational drugs and their neurological consequences," Journal of Neurology, Neurosurgery \& Psychiatry, vol. 75, supplement 111, pp. iii9-iiil5, 2004.

[10] K. Esse, M. Fossati-Bellani, A. Traylor, and S. Martin-Schild, "Epidemic of illicit drug use, mechanisms of action/addiction and stroke as a health hazard," Brain and Behavior, vol. 1, no. 1, pp. 44-54, 2011.

[11] V. V. Upreti, N. D. Eddington, K.-H. Moon, B.-J. Song, and I. J. Lee, "Drug interaction between ethanol and 3,4-methylenedioxymethamphetamine ("ecstasy")," Toxicology Letters, vol. 188, no. 2, pp. 167-172, 2009.

[12] M. Izco, L. Orio, E. O'Shea, and M. I. Colado, "Binge ethanol administration enhances the MDMA-induced long-term 5-HT neurotoxicity in rat brain," Psychopharmacology, vol. 189, no. 4, pp. 459-470, 2007.

[13] C. L. Galindo, M. A. Skinner, M. Errami et al., "Transcriptional profile of isoproterenol-induced cardiomyopathy and comparison to exercise-induced cardiac hypertrophy and human cardiac failure," BMC Physiology, vol. 9, no. 1, article no. 23, 2009.

[14] L. C. Heather, A. F. Catchpole, D. J. Stuckey, M. A. Cole, C. A. Carr, and K. Clarke, "Isoproterenol induces in vivo functional and metabolic abnormalities; similar to those found in the infarcted rat heart," Journal of Physiology and Pharmacology, vol. 60, no. 3, pp. 31-39, 2009.

[15] X. Li, R. Zhou, P. Zheng et al., "Cardioprotective effect of matrine on isoproterenol-induced cardiotoxicity in rats," Journal of Pharmacy and Pharmacology, vol. 62, no. 4, pp. 514-520, 2010.

[16] K. S. Kumaran and P. S. M. Prince, "Preventive effect of caffeic acid on lysosomal dysfunction in isoproterenol-induced myocardial infarcted rats," Journal of Biochemical and Molecular Toxicology, vol. 24, no. 2, pp. 115-122, 2010.

[17] L. Vennila and K. V. Pugalendi, "Efficacy of sesamol on plasma and tissue lipids in isoproterenol-induced cardiotoxicity in Wistar rats," Archives of Pharmacal Research, vol. 35, no. 8, pp. 1465-1470, 2012.

[18] G. Lalitha, P. Poornima, A. Archanah, and V. V. Padma, "Protective effect of neferine against isoproterenol-induced cardiac toxicity," Cardiovascular Toxicology, vol. 13, no. 2, pp. 168-179, 2013.

[19] H. Pipaliya and J. Vaghasiya, "Cardio protective effect of vitamin A against isoproterenol-induced myocardial infarction," Journal 
of Nutritional Science and Vitaminology, vol. 58, no. 6, pp. 402407, 2012.

[20] A. Remla, P. V. G. Menon, P. A. Kurup, and S. Kumari, "Effect of ethanol administration on metabolism of lipids in heart and aorta in isoproterenol induced myocardial infarction in rats," Indian Journal of Experimental Biology, vol. 29, no. 3, pp. 244248, 1991.

[21] L. D. Gottlieb, R. I. Horwitz, M. L. Kraus, S. R. Segal, and C. M. Viscoli, "Randomized controlled trial in alcohol relapse prevention: role of atenolol, alcohol craving, and treatment adherence," Journal of Substance Abuse Treatment, vol. 11, no. 3 , pp. 253-258, 1994.

[22] M. Klapholz, “ $\beta$-blocker use for the stages of heart failure," Mayo Clinic Proceedings, vol. 84, no. 8, pp. 718-729, 2009.

[23] V. Hinstridge and T. M. Speight, "An overview of therapeutic interventions in myocardial infarction. Emphasis on secondary prevention," Drugs, vol. 42, no. 2, pp. 8-20, 1991.

[24] M. E. Pedersen and J. R. Cockcroft, "The vasodilatory betablockers," Current Hypertension Reports, vol. 9, no. 4, pp. 269277, 2007.

[25] M. A. A. Saad, A. M. Abbas, V. Boshra, M. Elkhateeb, and I. A. El Aal, "Effect of Angiotensin II Type 1 receptor blocker, Candesartan, and $\beta_{1}$ adrenoceptor blocker, Atenolol, on brain damage in ischemic stroke," Acta Physiologica Hungarica, vol. 97, no. 2, pp. 159-171, 2010.

[26] B. Filipek, J. Krupinska, T. Librowski, K. Zebala, I. Piasecka, and W. Peikoszewski, "The effect of ethanol on the antiarrhythmic action of atenolol," Polish Journal of Pharmacology and Pharmacy, vol. 41, no. 3, pp. 207-211, 1989.

[27] H. Douard, B. Mora, and J.-P. Broustet, "Comparison of the antianginal efficacy of nicardipine and nifedipine in patients receiving atenolol: a randomized, double-blind, crossover study," International Journal of Cardiology, vol. 22, no. 3, pp. 357-363, 1989.

[28] L. D. Gottlieb, "The role of beta blockers in alcohol withdrawal syndrome," Postgraduate Medicine, no. 169-174, 1988.

[29] R. I. Horwitz, L. D. Gottlieb, and M. L. Kraus, "The efficacy of atenolol in the outpatient management of the alcohol withdrawal syndrome. Results of a randomized clinical trial," Archives of Internal Medicine, vol. 149, no. 5, pp. 1089-1093, 1989.

[30] B. A. Johnson, "The role of serotonergic agents as treatments for alcoholism," Drugs of Today, vol. 39, no. 9, pp. 665-672, 2003.

[31] Y. Sato, M. Kaji, N. Metoki, H. Yoshida, and K. Satoh, "Coagulation-fibrinolysis abnormalities in patients receiving antiparkinsonian agents," Journal of the Neurological Sciences, vol. 212, no. 1-2, pp. 55-58, 2003.

[32] M. Sandler, S. B. Carter, K. R. Hunter, and G. M. Stern, "Tetrahydroisoquinoline alkaloids: in vivo metabolites of Ldopa in man," Nature, vol. 241, no. 5390, pp. 439-443, 1973.

[33] M. Hirst, D. R. Evans, C. W. Gowdey, and M. A. Adams, "The influences of ethanol and other factors on the excretion of urinary salsolinol in social drinkers," Pharmacology Biochemistry and Behavior, vol. 22, no. 6, pp. 993-1000, 1985.

[34] J. Adachi, Y. Mizoi, T. Fukunaga, M. Kogame, I. Ninomiya, and T. Naito, "Effect of acetaldehyde on urinary salsolinol in healthy man after ethanol intake," Alcohol, vol. 3, no. 3, pp. 215-220, 1986.

[35] M. Naoi, W. Maruyama, and G. M. Nagy, "Dopamine-derived salsolinol derivatives as endogenous monoamine oxidase inhibitors: occurrence, metabolism, and function in human brains," NeuroToxicology, vol. 25, no. 1-2, pp. 193-204, 2004.
[36] W. Maruyama, G. Sobue, K. Matsubara, Y. Hashizume, P. Dostert, and M. Naoi, "A dopaminergic neurotoxin, $1(\mathrm{R}) 2(\mathrm{~N})$ dimethyl-6,7-dihydroxy-1,2,34-tetrahydroisoquinoline, $\mathrm{N}$-methyl (R) salsolinol and its oxidation product, 1,2(N)dimethyl-6,7-dihydroxyisquinolinium ion, accumulate in the nigro-straiatal system of the human brain," Neuroscience Letters, vol. 223, pp. 61-64, 1997.

[37] P. Batel, "The treatment of alcoholism in France," Drug and Alcohol Dependence, vol. 39, supplement 1, pp. S15-S21, 1995.

[38] R. C. Elliott and J. P. Quilliam, "Some actions of centrally active and other drugs on the transmission of single nerve impulses through the isolated superior cervical ganglion preparation of the rabbit," British Journal of Pharmacology and Chemotherapy, vol. 23, pp. 222-240, 1964.

[39] D. A. Brown and J. P. Quilliam, "The effects of some centrally acting drugs on ganglionic transmission in the cat," The British Journal of Pharmacology and Chemotherapy, vol. 23, pp. 241256, 1964.

[40] D. A. Brown and J. P. Quillian, "Observations on the mode of action of some central depressant drugs on transmission through the cat superior cervical ganglion," British Journal of Pharmacology, vol. 23, pp. 257-272, 1964. 


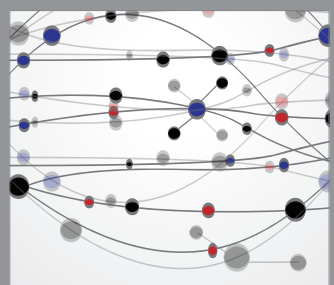

The Scientific World Journal
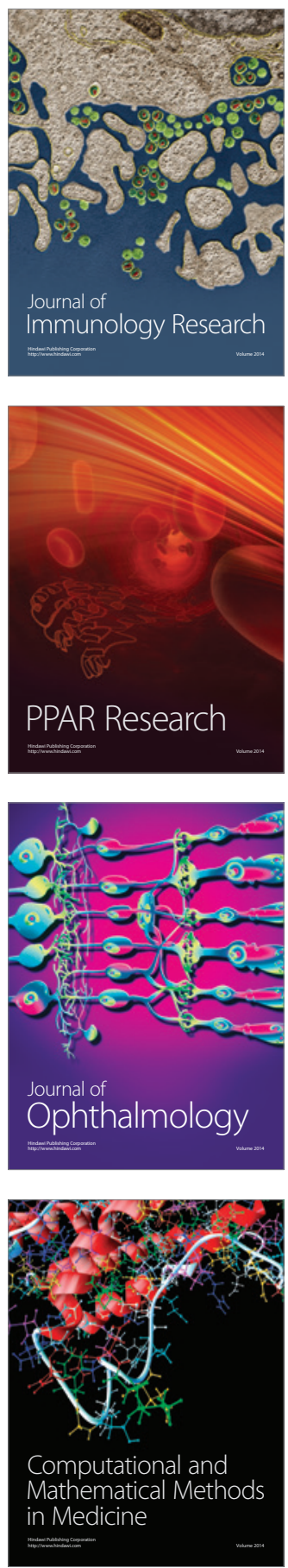

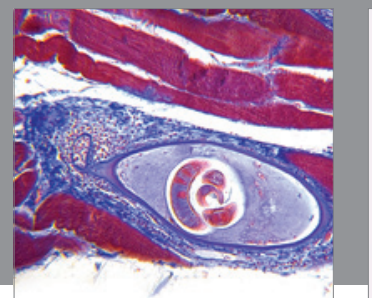

Gastroenterology

Research and Practice
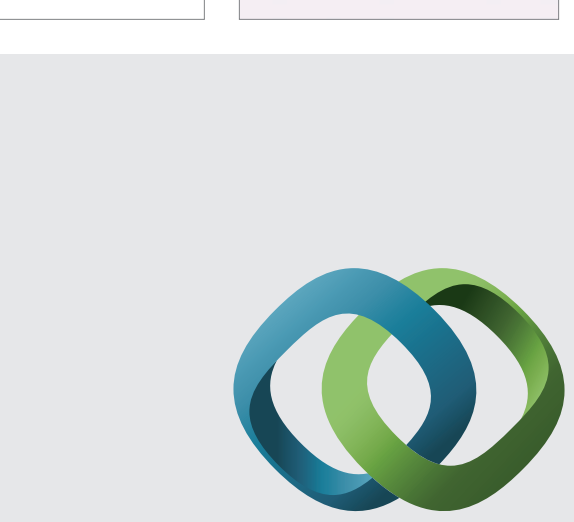

\section{Hindawi}

Submit your manuscripts at

http://www.hindawi.com
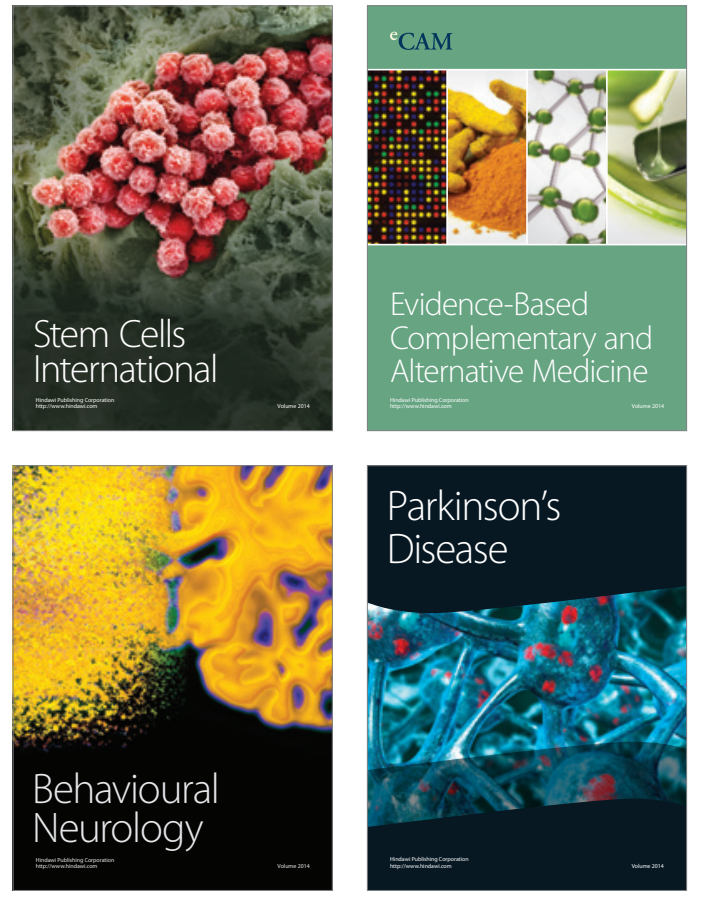
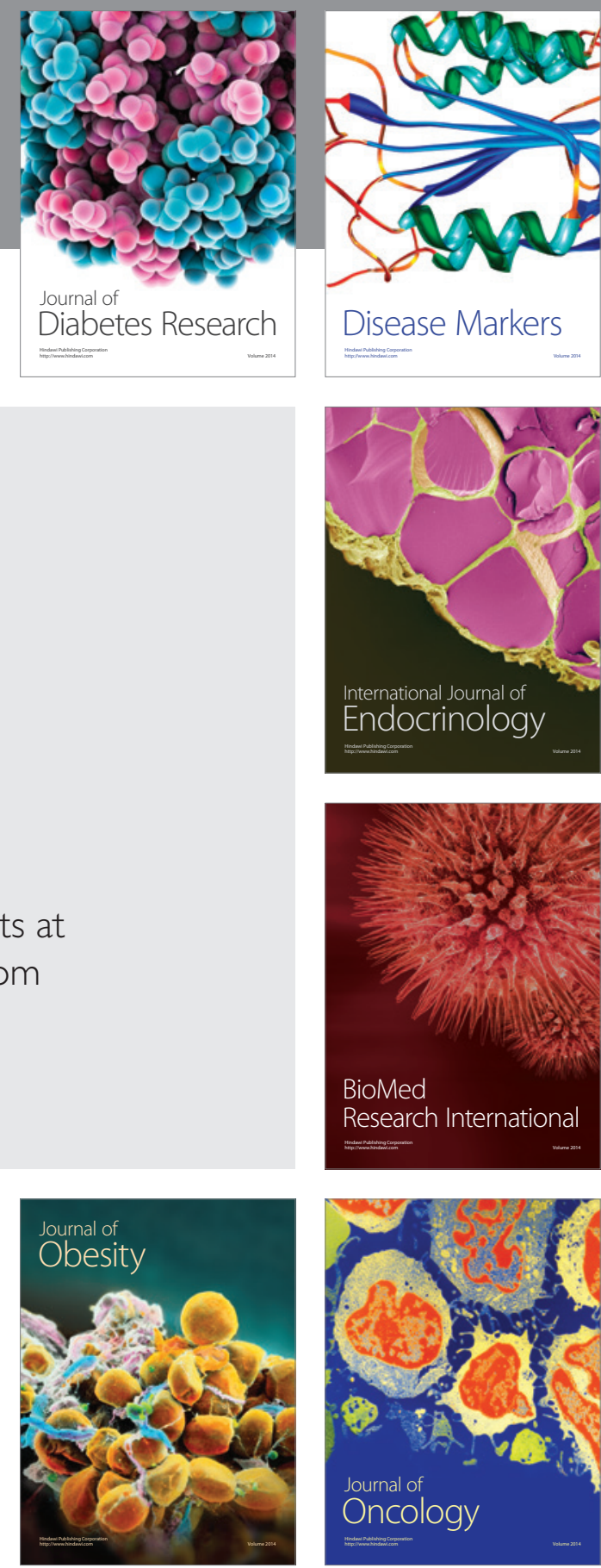

Disease Markers
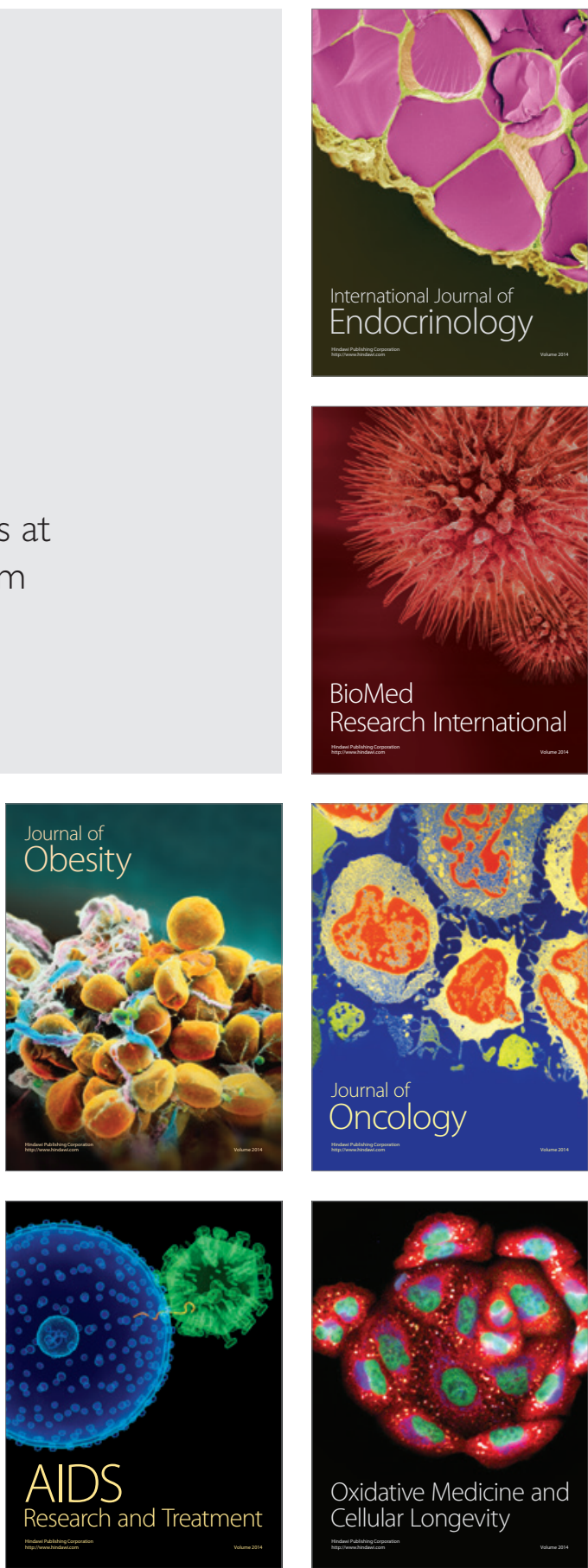